\title{
Profit efficiency of smallholder rubber farmers in Kegalle, Kalutara and Ratnapura districts
}

\author{
Jagath Edirisinghe*, Wasana Wijesuriya** and C Bogahawatte*** \\ * Faculty of Agriculture and Plantation Management, Wayamba University of Sri Lanka, \\ Makandura, Sri Lanka \\ ** Rubber Research Institute of Sri Lanka, Dartonfield, Agalawatta, Sri Lanka \\ *** Dept. of Agricultural Economics, Faculty of Agriculture, University of Peradeniya, \\ Peradeniya, Sri Lanka
}

(Received 27 July 2010: Accepted 24 February 2011)

\begin{abstract}
In this paper, we examined the profit efficiency of smallholder rubber cultivators in Sri Lanka. Profit efficiency is central to an export oriented product such as rubber in the light of structural adjustment policies, viz. market liberalisation and currency devaluation. We employed a profit frontier to a cross section of farmers from three major rubber growing districts; Kegalle, Kalutara and Ratnapura. In doing so, we tested and assessed the adequacy of common model assumptions in the composed error literature. In our data set, we have found that the distributional assumption for the inefficiency term is immaterial in the ranking of farmers according to their levels of efficiency. Results further showed that the average profit efficiency in smallholder rubber farmers was 61.8 percent implying that around 38 percent improvement in efficiency could be achieved without any increase in costs. The major determinants of inefficiency are found to be the education levels of farmers, age (experience), type of clone planted and the type of output.
\end{abstract}

Key words: profit efficiency, rubber, smallholders

\section{Introduction}

A common feature in most plantation crops is that there is no possibility of home consumption. Hence, profit maximisation is the major objective of rubber cultivators even in the smallholder sector. Farmers' input choices are therefore, shaped by this primal objective. As rubber cultivations have been in Sri Lanka for generations, it is reasonable to assume that the production technology has diffused into all farmers analogously. Yet, in time and again, we hear that farmers give up rubber cultivation; the common culprit being the low profitability (Wijesuriya et al., 2007). Nevertheless, the majority remains, indicating sufficient profits are generated for those. The natural question arising then is, if we can safely 
Jagath Edirisinghe et al.

assume that farmers have common production technology, why do some farmers achieve 'higher' levels of profit, while others do not? In other words, this implies that, there is a maximum possible level of profit that can be achieved given the technology and resource endowments and some farmers may achieve this maximum and others may fall below it to varying degrees. It is logical then to ask; by how much is the shortfall in profits from the maximum possible? In other words, how much profit is foregone by smallholder farmers, which they could have otherwise obtained? These types of questions are handled in efficiency literature (Bravo-Ureta and Pinheiro 1993; Murillo-Zamorano 2004). Therefore, our central objective in this study was to assess the levels of profit efficiency in the smallholder rubber sector using the developments in the efficiency literature.

\section{Methodology}

Efficiency is defined in three forms; economic, pricing (allocative) and technical. Economic efficiency results from the joint interaction of price and technical efficiency (Hollas and Stansell 1988). Literature is abundant with empirical investigations of efficiency. Most common are on technical efficiency that attempt to study the ability of a firm to obtain maximum output from a given set of inputs. This entails an estimation of a production frontier, composed of twin error terms, one of which is assumed to be the random disturbance while the other is assumed to be the inefficiency. Excellent reviews of efficiency literature can be found in Bravo-Ureta and Pinheiro (1993) and MurilloZamorano (2004). Yet, Abdulai and Huffman (2000) states "a production approach however, fails to capture inefficiencies associated with different factor endowments and different input and output prices across firms. Under such conditions, farms may exhibit different 'best practice' production functions and operate at different optimal points". Using a profit frontier, the economic efficiency can be directly studied as the ability of the farmer to achieve the potential maximum profit, given the levels of fixed factors and prices faced by the farmer (Abdulai and Huffman 2000). Thus, we focused on the profit frontier to estimate the profit efficiency.

Profit efficiency can be formalised as follows. If we assume that producers seek to maximise profit, (p'y-w'x) by producing the output, $\mathrm{y}$ using inputs, $\mathrm{x}$, facing output prices $\mathrm{p} \in \mathrm{R}_{++}^{\mathrm{M}}$ and input prices $\mathrm{W} \in \mathrm{R}_{++}^{\mathrm{M}}$, the profit efficiency can be stated as $\left(p^{\prime} y^{-}-w^{\prime} x\right) / v \pi(p, w, A)$, where the numerator specifies the actual variable profits while the denominator specifies the variable profit frontier (Kumbhakar and Lovell 2003). The variable profit frontier is defined here because we are working with cross sectional data and there always will be fixed factors, (A) that do not vary in the 
short run. Two paths are available to estimate the profit efficiency; the use of primal production frontiers and the use of the dual profit frontier (Kumbhakar and Lovell 2003). We used a dual profit frontier in this study. Lau (1976) provides the basic framework for a normalised profitfunction, where the normalisation achieves the 'well behaviour', including non-increasing in input prices, non-decreasing in output prices, homogeneity of degree zero in input and output prices and convexity in input and output prices. The normalised profit function $\pi(\mathbf{p}, \mathbf{z})$ can be;

$$
\begin{aligned}
\pi(\mathbf{p}, \mathbf{z})=\mathrm{y}\left(\mathrm{x}^{*}, \mathrm{z}\right) & \\
& -\sum_{\mathrm{i}} \mathrm{p}_{\mathrm{i}} \mathrm{x}_{\mathrm{i}}^{*}, \mathrm{x}^{*} \\
=\mathrm{g}(\mathrm{p}, \mathrm{z}) &
\end{aligned}
$$

Where, $p_{i}$ is the input price normalised on the output price and ' $*$ ' denotes the optimum input quantities. Keeping in line with the composed error models used in stochastic frontier analysis, the stochastic profit frontier can be specified by incorporating a random error, $u_{i}$ and the displacement from the profit frontier, $\mathrm{z}_{\mathrm{i}}$.

$$
\pi_{\mathrm{i}}=f\left(\mathrm{p}_{\mathrm{ji}}, \mathrm{A}_{\mathrm{ki}}\right) \cdot \exp \left(\mathrm{u}_{\mathrm{i}}-\mathrm{z}_{\mathrm{i}}\right)
$$

Where, $\pi_{\mathrm{i}}$ is the normalised profit of the $i^{\text {th }}$ farmer, $p_{\mathrm{ji}}$ is the normalised price of the $\mathrm{j}^{\text {th }}$ input used by the $\mathrm{i}^{\text {th }}$ farmer. Fixed inputs are denoted by $\mathrm{A}_{\mathrm{i}}$. As is in the standard composed error framework, $u_{i}$ is normally distributed with a constant variance, $\mathrm{u}_{i} \sim N\left(0, \sigma_{\mathrm{u}}\right)$. The $\mathrm{z}_{\mathrm{i}}$ is the one sided error depicting the displacement from the frontier. Of considerable interest in the literature is the choice of distributional assumption of $z_{i}$ and the functional form. The common distributional assumption of $z_{i}$ are, halfnormal, truncated normal, exponential and gamma (Kumbhakar and Lovell 2003). The most common functional forms include the Cobb-Douglas and the translog function. To accommodate this uncertainty with respect to the distribution of the inefficiency term and the functional form on the estimated efficiencies, four models are estimated: a Cobb-Douglas and a translog form with half normal and truncated normal distributions. The econometric specification of the Cobb-Dougles model used is,

$$
\begin{gathered}
\ln \pi_{\mathrm{i}}=\beta_{0}+\sum_{\mathrm{j}=1}^{4} \beta_{\mathrm{j}} \ln \mathrm{p}_{\mathrm{ij}} \\
+\beta_{\mathrm{A}} \ln \mathrm{A}_{\mathrm{i}}+\mathrm{u}_{\mathrm{i}} \\
-\mathrm{z}_{\mathrm{i}}
\end{gathered}
$$

The translog model is,

$\ln \pi_{\mathrm{i}}$

$$
\begin{aligned}
& =\beta_{0} \sum_{\mathrm{i}=1}^{4} \beta_{\mathrm{j}} \ln \mathrm{p}_{\mathrm{ij}} \\
& +\frac{1}{2} \sum_{\mathrm{l}=1}^{4} \sum_{\mathrm{m}=1}^{4} \beta_{\mathrm{jk}} \ln \mathrm{pli}_{\mathrm{li}} \ln \mathrm{p}_{\mathrm{mi}} \\
& +\beta_{\mathrm{A}} \ln \mathrm{A}_{\mathrm{i}}+\mathrm{u}_{\mathrm{i}}-\mathrm{z}_{\mathrm{i}}
\end{aligned}
$$

Where, $\mathrm{p}_{\mathrm{i}}$ includes normalised prices of four inputs used in production of rubber (labour, fuel, chemicals and fertilizer). Land extent is used as the fixed input, 
$\mathrm{A}_{\mathrm{i}}$. The comparison of efficiency predictions from half and truncated normal models are carried out using a Likelihood Ratio test (LR test). The LR test statistic $(\lambda)$ is calculated using the following formula,

$$
\begin{aligned}
\lambda=-2\left[\ln \frac{\mathrm{L}\left(\mathrm{H}_{0}\right)}{\mathrm{L}\left(\mathrm{H}_{1}\right)}\right] & \\
& =-2\left[\operatorname{lnL}\left(\mathrm{H}_{0}\right)\right. \\
& \left.-\operatorname{lnL}\left(\mathrm{H}_{1}\right)\right]
\end{aligned}
$$

The LR test compares the fit of two models. The likelihood ratio calculated as above expresses how many times more likely the data are under one model than the other. The LR test statistic, $\lambda$, can be compared to a critical value to decide whether to reject the null model in favour of the alternate model. The probability distribution of the test statistic is approximately a chisquare distribution with degrees of freedom equal to the difference between the degrees of freedom of the two models considered.

In order to assess the determinants of inefficiency, the efficiencies and determinants of efficiency were estimated jointly using the software, FRONTIER 4.1. Farmer specific factors as well as the farm specific factors were used in order to explain inefficiency. They are listed below together with abbreviations.

AGEFAR age of the farmer in years

$D A L \quad$ dummy for education (If Advanced Level $(\mathrm{A} / \mathrm{L})$ and higher $=1$; otherwise $=0$ )

$D O L \quad$ dummy for education (If less than or equal to Ordinary Level $(\mathrm{O} / \mathrm{L})$ and more than primary $=1$; Otherwise $=0$ )

EXT extent of mature rubber area in acres

DRRIC121 dummy for clone (If clone is RRIC121 $=1$; otherwise $=0$ )

DRRIC100 dummy for clone (If RRIC100 $=1$; otherwise $=0$ )

TAPLAB dummy for type of labour used (If hired labour $=1$; family labour $=0$ )

outTYPE dummy for type of output (If sheet rubber $=1$; rubber latex $=0$ )

DISMARK distance to market in kilometres

OCCUP No. of members in the family who are occupied

\section{Data}

For the development of profit function, cross sectional data were collected from three major rubber growing regions in the country. A multistage sampling scheme was used in the study in the following manner. The total sample size was restricted to 1,000 considering the limitations on expenses. The total is divided among the three regions studied on the basis of number of smallholders in each area. Accordingly, the sample is divided among Kalutara, Kegalle and Ratnapura districts on the ratio $7: 10: 3$ and the samples of size 350, 500 and 150 were collected from each region 
respectively. From each region, five RDO (Rubber Development Officers) divisions were selected to collect data. The RDO divisions were selected in accordance with the dispersion in the region to best represent the region geographically. The interviews were conducted by Rubber Extension Officers attached to the Advisory Services Department of the Rubber Research Institute of Sri Lanka (RRISL). Though, a sample of 1000 farmers was selected, only 545 could be used in the analysis as complete information on prices were not available in the full data set. The final sample used in the analysis consisted of 171 farmers from the Kalutara district, 170 from the Kegalle district and 204 from the Ratnapura district. The questionnaire consisted of information on personal data on farmers, technical data on the rubber farms such as extents, inputs used and output produced, revenue and costs from rubber cultivation, and input and output prices. The summary statistics of the variables used in the profit function are given in Table 1. The analysis was carried out by using the computer programme, FRONTIER 4.1 (Coelli 1996).

\section{Results and Discussion Nature of production}

The summary statistics for inputs which are necessary for the estimation of profit function is given in Table 1. The farmers in the study area produced two main types of output; Ribbed Smoked
Sheets (RSS) and latex. Those farmers who sell their output as latex did not incur costs for rolling and smoking rubber sheets. There are four major types of inputs that are used in rubber production at the smallholder level. The most important is labour, which is used mostly for tapping and accounts for a higher portion of the total cost of production. In addition fertilizer, chemicals for rubber sheet production and fuel wood for smoking rubber sheets are the other major inputs used by the farmers. The average prices that the farmers pay for these are included in the Table 1. Though there is a specific wage rate for all plantation crops mostly at estate level or at smallholder level, farmers pay for labour wages in different ways. Some pay a wage rate as in the estates but others pay half of the day's income as the wage for tapping. Hence, for some farmers, labour wages are absorbed into their profits. The cost of production of rubber vary depend on the type of output produced by the smallholders. The latex producers who do not incur the costs of smoking and drying of rubber sheets have generally a low cost of production while the sheet producers have a higher cost of production. The highest cost of production was observed in Kegalle district for producing both forms of rubber. The lowest was observed in the Ratnapura district. The average cost of production of rubber was $\mathrm{Rs} .63 .27 / \mathrm{kg}$ and Rs.51.45/kg for RSS and latex respectively (Table 1). 
Table 1. Summary production statistics

\begin{tabular}{lcccc}
\hline Item & \multicolumn{3}{c}{ District } & All \\
\cline { 2 - 4 } & Kalutara & Kegalle & Ratnapura & \\
\hline Wage rate (Rs/Manday) & 294.28 & 393.31 & 250.10 & 312.66 \\
Fertilizer price (Rs/kg) & $(11.88)$ & $(16.72)$ & $(5.66)$ & $(7.48)$ \\
& 15.80 & 12.16 & 12.84 & 674.34 \\
Chemical Price (Rs/lt) & $(0.58)$ & $(0.44)$ & $(0.71)$ & $(0.35)$ \\
Fuel Wood price (Rs/Yard) & 170.06 & 167.50 & 176.35 & 171.70 \\
& $(2.30)$ & $(1.06)$ & $(3.56)$ & $(1.59)$ \\
Output prices & 735.66 & 522.30 & 695.87 & 660.43 \\
Latex (Rs/kg) & $(17.80)$ & $(29.44)$ & $(12.97)$ & $(12.28)$ \\
& & & & \\
Sheet (Rs/kg) & 189.50 & 182.68 & 192.28 & 187.75 \\
& $(2.22)$ & $(2.07)$ & $(4.45)$ & $(1.59)$ \\
Average Profit (Rs./ac./month) & 200.41 & 195.91 & 198.77 & 198.26 \\
Latex & $(1.92)$ & $(1.73)$ & $(1.43)$ & $(0.96)$ \\
Sheet & 5830 & 6042 & 10552 & 7352.38 \\
& $(530.26)$ & $(991.95)$ & $(1023.69)$ & $(514.26)$ \\
Cost of production (Rs/kg) & 7316 & 5434 & 8300 & 7053 \\
Latex & $(335.97)$ & $(416.41)$ & $(315.39)$ & $(215.21)$ \\
Sheet & 46.77 & 75.18 & 39.87 & 51.45 \\
No. of observations (N) & $(2.09)$ & $(5.26)$ & $(3.37)$ & $(2.41)$ \\
& 55.03 & 80.30 & 52.12 & 63.27 \\
& $(1.33)$ & $(1.43)$ & $(1.74)$ & $(0.99)$ \\
& 172 & 170 & 204 & 545 \\
\hline
\end{tabular}

Note: All data pertain to the year 2007

Figures within the parentheses are standard errors

\section{Efficiency levels}

The mean levels of efficiency under different model assumptions are presented in Table 2. Although, there is a slight difference in the mean efficiency predictions, the maximum and minimum efficiencies predicted are quite comparable suggesting that the distribution of error terms are related under each model assumption.
This implies that although, there was a slight discrepancy between mean efficiency predictions, the ranking of farmers according to profit efficiency is comparable under all models. Previous studies on technical efficiency are in line with this finding (Ahmad and Bravo-Ureta 1996).

To further test whether the assumption on the distribution of the inefficiency 
term (Truncated Normal and Half Normal), has a bearing on the frontiers estimated, the log likelihood values obtained from the maximum likelihood estimations are compared using a formal Likelihood Ratio (LR) test using equation 5, where, $\operatorname{Ln} L\left(\mathrm{H}_{0}\right)$ is the $\log$ likelihood of the restricted model (Half Normal Model) and $\operatorname{Ln} L\left(\mathrm{H}_{1}\right)$ is the $\log$ likelihood of the unrestricted function (Truncated Normal model). The LR statistic calculated for each model is not significantly different from each other (Table 3). That is, under each functional form, either the use of truncated normal or half normal assumption does not seem to have an effect on the frontier results.

Because the estimations under the halfNormal and the truncated-Normal assumptions did not show a difference in the frontier estimated, only the maximum likelihood results under the
truncated-Normal assumption are reported in Table 4. Based on the results, choosing the functional form that best fit the data is trivial. As CobbDouglas is contained within the translog form, significance of cross product terms can be used to assess whether the translog is better than the Cobb-Douglas model. Accordingly, because most of the cross product terms are nonsignificant, the Cobb-Douglas form performs better in the present context. The higher variance ratio $(\gamma)$ indicates that the one sided error term depicting the displacement from the frontier dominates the random error implying that the variation in profit is mainly due to inefficiency. All prices return the expected negative sign keeping in line with the regularity conditions of a profit function. The fixed input (Land) returns the anticipated positive sign.

Table 2. Mean efficiencies of different models

\begin{tabular}{lllll}
\hline Functional form & Inefficiency distribution & Min & Mean & Max \\
\hline Translog & Truncated normal & 0.15 & 0.67 & 0.89 \\
Translog & Half normal & 0.14 & 0.63 & 0.89 \\
Cobb Douglas & Truncated normal & 0.14 & 0.64 & 0.90 \\
Cobb Douglas & Half normal & 0.14 & 0.69 & 0.90 \\
\hline
\end{tabular}

No. of observations $=545$

Table 3. Results of likelihood ratio test

\begin{tabular}{ll}
\hline Functional Form & LR statistic \\
\hline Translog & 0.26 \\
Cobb-Douglas & 0.04 \\
\hline
\end{tabular}

Critical value at $1 \%$ level $=6.63$ at d.f. $=1$ 
Jagath Edirisinghe et al.

Table 4. Maximum likelihood estimates of the profit frontier

\begin{tabular}{|c|c|c|c|c|c|c|}
\hline \multirow{3}{*}{ Model terms } & \multicolumn{6}{|c|}{ Model form } \\
\hline & \multicolumn{3}{|c|}{ Cobb-Douglas } & \multicolumn{3}{|c|}{ Translog } \\
\hline & Estimate & Std Error & $\mathrm{T}$ ratio & Estimate & Std error & T ratio \\
\hline Constant & 4.031 & 0.260 & $15.51^{* * *}$ & 3.948 & 0.165 & $23.8^{* *}$ \\
\hline Extent(EXT) & 0.864 & 0.157 & $5.51^{* *}$ & 0.681 & 0.0995 & $6.85^{*}$ \\
\hline Wage Rate(WR) & -0.233 & 0.033 & $-7.05^{* *}$ & -0.177 & 0.1536 & -1.16 \\
\hline Fertilizer price (FP) & -0.099 & 0.017 & $-5.69^{* *}$ & 0.010 & 0.1332 & 0.079 \\
\hline Chemical Price(CP) & -0.002 & 0.110 & -0.021 & 0.041 & 0.255 & 0.16 \\
\hline Fuel price (FUP) & -0.047 & 0.320 & -0.147 & -0.059 & 0.1147 & -0.52 \\
\hline $\mathrm{EXT} \times \mathrm{EXT}$ & & & & 0.114 & 0.0443 & $2.58^{* *}$ \\
\hline $\mathrm{WR} \times \mathrm{WR}$ & & & & 0.030 & 0.0736 & 0.41 \\
\hline $\mathrm{FP} \times \mathrm{FP}$ & & & & 0.022 & 0.0463 & 0.47 \\
\hline $\mathrm{CP} \times \mathrm{CP}$ & & & & -0.046 & 0.0657 & -0.70 \\
\hline FUP $\times$ FUP & & & & 0.128 & 0.0675 & $1.89^{*}$ \\
\hline $\mathrm{EXT} \times \mathrm{WR}$ & & & & -0.041 & 0.0807 & -0.51 \\
\hline $\mathrm{EXT} \times \mathrm{FP}$ & & & & -0.026 & 0.0248 & -1.06 \\
\hline $\mathrm{EXT} \times \mathrm{CP}$ & & & & -0.147 & 0.1746 & -0.85 \\
\hline $\mathrm{EXT} \times \mathrm{FUP}$ & & & & -0.083 & 0.0546 & -1.52 \\
\hline $\mathrm{WR} \times \mathrm{FP}$ & & & & -0.028 & 0.044 & -0.66 \\
\hline $\mathrm{WR} \times \mathrm{CP}$ & & & & -0.363 & 0.3788 & -0.96 \\
\hline $\mathrm{WR} \times \mathrm{FUP}$ & & & & -0.079 & 0.1105 & -0.72 \\
\hline $\mathrm{FP} \times \mathrm{CP}$ & & & & -0.061 & 0.1019 & -0.59 \\
\hline $\mathrm{FP} \times \mathrm{FUP}$ & & & & -0.019 & 0.0295 & -0.64 \\
\hline $\mathrm{CP} \times \mathrm{FUP}$ & & & & -0.023 & 0.2218 & -0.10 \\
\hline$\sigma^{2}($ total variance $)$ & 0.659 & 0.223 & $2.956^{* *}$ & 0.781 & 0.5904 & 1.32 \\
\hline$\gamma($ variance ratio $)$ & 0.790 & 0.076 & $10.4^{* * *}$ & 0.804 & 0.1201 & $6.69^{* *}$ \\
\hline$\lambda$ (likelihood ratio) & 31.15 & & & 13.83 & & \\
\hline $\mathrm{N}$ & 545 & & & & & \\
\hline
\end{tabular}

${ }^{*}$ Significant at $10 \%{ }^{* *}$ Significant at $5 \%$

The profit efficiency levels of the sample studied range had a mean of $61.8 \%$ and a standard deviation of 16.2. This implies that $38 \%$ of the potential maximum profit is lost due to inefficiency. This difference between the observed and the frontier profit is due to both the technical and the allocative inefficiencies. Table 5 shows the efficiency levels of farmers in the sample. It is clear that the rubber farmers are profit inefficient in all the three districts. This may be one of the major reasons for abandoning rubber cultivation by rubber smallholders. 
Profit efficiency of smallholder farmers

Table 5. Frequency distribution of farm specific profit efficiencies in stochastic CobbDouglas frontier

\begin{tabular}{|c|c|c|c|c|c|c|c|c|}
\hline \multirow[b]{3}{*}{$\begin{array}{l}\text { Efficiency } \\
(\%)\end{array}$} & \multicolumn{6}{|c|}{ District } & \multirow{3}{*}{$\begin{array}{l}\text { Total } \\
\text { No. of } \\
\text { farmers }\end{array}$} & \multirow[b]{3}{*}{$\%$} \\
\hline & \multicolumn{2}{|l|}{ Kalutara } & \multicolumn{2}{|c|}{ Kegalle } & \multicolumn{2}{|c|}{ Ratnapura } & & \\
\hline & $\begin{array}{l}\text { No. of } \\
\text { farmers }\end{array}$ & $\%$ & $\begin{array}{l}\text { No. of } \\
\text { farmers }\end{array}$ & $\%$ & $\begin{array}{l}\text { No. of } \\
\text { farmers }\end{array}$ & $\%$ & & \\
\hline $11-20$ & 1 & 0.58 & 1 & 0.59 & 2 & 0.98 & 4 & 0.73 \\
\hline $21-30$ & 4 & 2.34 & 13 & 7.65 & 2 & 0.98 & 19 & 3.49 \\
\hline $31-40$ & 6 & 3.51 & 23 & 13.53 & 9 & 4.41 & 38 & 6.97 \\
\hline $41-50$ & 24 & 14.04 & 32 & 18.82 & 15 & 7.35 & 71 & 13.03 \\
\hline $51-60$ & 34 & 19.88 & 37 & 21.76 & 19 & 9.31 & 90 & 16.51 \\
\hline $61-70$ & 37 & 21.64 & 41 & 24.12 & 39 & 19.12 & 117 & 21.47 \\
\hline $71-80$ & 47 & 27.49 & 15 & 8.82 & 80 & 39.22 & 142 & 26.06 \\
\hline $81-90$ & 18 & 10.53 & 8 & 4.71 & 38 & 18.63 & 64 & 11.74 \\
\hline Minimum & & $18.3 \%$ & & $14.0 \%$ & & $13.4 \%$ & & $13.4 \%$ \\
\hline Maximum & & $88.4 \%$ & & $86.79 \%$ & & $89.5 \%$ & & $89.5 \%$ \\
\hline Mean & & $62.8 \%$ & & $53.3 \%$ & & $68.1 \%$ & & $61.8 \%$ \\
\hline
\end{tabular}

The profit efficiency in the Kalutara district is distributed with a mean of $62.8 \%$ and a standard deviation of 14.8 . There are a few farmers who have efficiency levels less than 50\% and the distribution is skewed to the left (Fig. 1). The average efficiency levels are closer to the overall average and this is expected as Kalutara has been a traditional rubber growing district in the country. According to the results, Kegalle district performs poor, relatively to the other two districts. The mean efficiency of $53.3 \%$ is poor indicating that almost half of the profits that could have been obtained by farmers have been lost due to inefficiency.

The highest mean efficiency is found to be in the Ratnapura District. The distribution is slightly skewed to the left. In comparison to Kalutara and Kegalle districts, the Ratnapura district has a relatively higher percentage (18\%) in the higher efficiency levels (between efficiency categories $81 \%$ - 90\%). However, none of the districts showed efficiency levels of more than 90 percent.

Reasons for profit inefficiency of rubber smallholders

In order to find the reasons for inefficiency, farmer and farm related factors were simultaneously estimated with the profit frontier. The results are indicated in Table 6. The age of the household head is significant with negative sign as expected. This would mean that the older farmers who have more experience in rubber cultivation would make proper decisions in 
Jagath Edirisinghe et al.

resource allocation than their younger counterparts. Education dummies used were also found to be significant with negative sign implying that educated farmers were more efficient. For achieving profit efficiency, reallocation of resources with changing economic conditions is vital. Education provides this by enabling the farmers to (a) perceive that a change has occurred (b) collect, retrieve and analyze useful information (c) drawing valid conclusions from available information and (d) act quickly and decisively (Abdulai and Huffman 2000). This also is in line with other similar studies such as Basnayake and Guneratne (2001) in tea smallholding sector in Sri Lanka and Ali and Flinn (1989) in Pakistan for rice production.

Table 6. Determinants of profit inefficiency in the three districts studied as per stochastic Cobb-Douglas frontier

\begin{tabular}{lrcl}
\hline Variable & Coefficient & Standard error & \multicolumn{1}{c}{$\mathrm{t}$ ratio } \\
\hline (Constant) & 0.079 & 0.009 & $8.936^{* *}$ \\
AGEFAR & -0.108 & 0.055 & $-1.953^{*}$ \\
DAL & -0.22 & 0.076 & $-2.917^{* *}$ \\
DOL & -0.055 & 0.029 & $-1.89^{*}$ \\
EXT & 0.152 & 0.958 & 0.159 \\
DRRIC121 & -0.440 & 0.069 & $-6.36^{* *}$ \\
DRRIC100 & -0.142 & 0.085 & $-1.67^{*}$ \\
TAPPLAB & 0.044 & 0.276 & 0.160 \\
OutTYPE & 0.296 & 0.073 & $4.073^{* *}$ \\
DISMARK & 0.369 & 0.646 & 0.571 \\
OCCUP & 0.217 & 0.329 & 0.660 \\
\hline
\end{tabular}

${ }^{*}$ Significant at $10 \%{ }^{* *}$ Significant at $5 \%$

The dummies for clones were highly significant. The two clones included in the model were compared with PB 86 which was not included in the model. The negative signs for RRIC 121 and RRIC 100 implied that inefficiency was less with farmers who cultivated these two clones than the farmers who cultivated PB 86 (which is an older clone not recommended by RRISL any more). Hence, the misconception by smallholder farmers that PB 86 is better than high yielding clones such as RRIC 121 and RRIC 100 was not supported by this result. Family or hired labour used in the farms for tapping of rubber did not seem to have any impact on the efficiency indicated by the non 
significant co-efficient for TAPLAB. The dummy for the type of output was found to be significant and positive. This means that the farmers who produce sheet rubber was inefficient than those who sell latex. This can be expected since there is much inefficiency involved in selling sheet rubber. Profit is maximized when value of marginal product equals the price of inputs. For this to occur, the output price should be correctly specified. In production of Ribbed Smoked Sheets (RSS), the rubber sheet is graded visually and these are subjective. However, the market price paid is determined based on the grade. Thus, mostly the price for the correct grade is not obtained by the rubber farmers leading to inefficiency.

The distance to market was included hypothesizing that with the increase in the distance to market place, the inefficiency would increase. Though, not significant, the expected positive sign with inefficiency was observed in this variable.

The variable representing the number of family members occupied in off farm activities was positive. This is as expected as vital resources are lost by employment elsewhere.

In order to check whether the scale economies are present in terms of profit efficiency, the efficiency levels were plotted with the extent (Fig. 1). However, no relationship could be seen with the size of the holding and the levels of efficiency achieved. However, it should be noted that the farm sizes in the sample had a limited variation in terms of size of the holding as the sample was restricted to smallholder farmers (less than 4.5ha). Though, a relationship could not be observed with the economic efficiency and extent of land, profits derived were sensitive to the size of the land (Fig. 1).

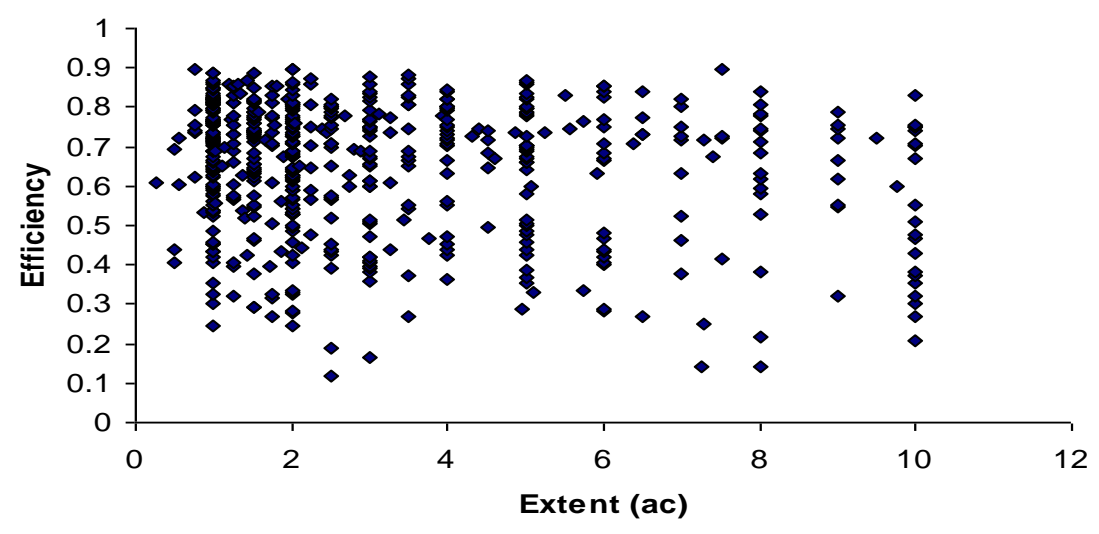

Fig. 1. Relationship of efficiency and the size of holding 
Jagath Edirisinghe et al.

\section{Conclusions}

One of the major problems in rubber cultivation is the heavy fluctuation of rubber prices. Rubber prices vary seasonally as well as cyclically. This variation leads to fluctuating income levels which are especially detrimental to smallholder rubber farmers. The repercussions of such fluctuating income levels were observed in the recent past where with low prices large number of smallholder rubber farmers abandoned their cultivations. Farmers who are efficient in allocating resources amidst the changing economic environment are likely to survive in this type of adverse situations. Hence, this study was carried out with the main objective of finding the profit efficiency of smallholder rubber farmers in Sri Lanka and to find out what leads to their inefficiency.

In this study, first the theoretical issue on the impact of functional forms and the assumption on the distribution of the one sided error term were tested. The results revealed that the efficiencies estimated are highly correlated irrespective of the functional form selected and distributional assumption of the error. Likelihood ratios estimated showed that there is no difference between the models estimated assuming a more general truncated normal distribution or a restricted half normal distribution for the error distribution.

The low efficiency values indicated that rubber farmers do not use their inputs in an efficient manner. The average efficiency of smallholder rubber farmers was 61.8 percent. This implied that around 32 percent improvement in efficiency could be achieved without any increases in costs. Further, there was a wide variation in efficiencies among the smallholders with a minimum of 13.4 percent and a maximum of 89.5 percent. This suggested an inefficiency range of $86.6 \%$ to $10.54 \%$. Thus, there is considerable loss of profit due to inefficiency. This range is similar in all the three districts.

The age and education level of farmers and the type of clone cultivated were found to be significant variables that increase the profit efficiency. Family members engaging in off farm activities, higher extent and production of sheet rubber than directly selling latex were found to lower the profit efficiency.

These findings have some important policy implications. The significance of education variable implies that perceiving and responding efficiently to changes in economic conditions require allocative ability that is acquired by investing in education and information. As education and age levels represented the levels of human capital, the results suggested that improvement of human capital could increase efficiency. Therefore, polices should be directed towards such improvement. The issue of availability of information is imperative here. While the allocative ability could be built upon improvement in information with respect to markets of both inputs and output such as 
development in prices, and demands, the information relating to conversion of input to output such as development of new production procedures, low cost production techniques, availability of planting material, recommendations of proper input use would improve the technical efficiency. In addition, as age represents experience of farmers gathered through a generation of rubber cultivation it improves efficiency because they have a greater ability of comprehension and making informed decisions. This ability can be created in farmers with lesser experience by way of training programmes, workshops organized by relevant stakeholders in the rubber sector such as RRISL and Rubber Development Department (RDD). The issue of better extension is highlighted here.

Another important finding is that with the contribution of new clones recommended by the Rubber Research Institute of Sri Lanka to increased economic efficiency. Such clones are the outcomes of long term investments in research and development from the government budget. Unfortunately, from time to time some governments cut down on research and development budgets hampering continuous research such as development of new clones which take long periods (close to 15-20 years). This finding confirms that these investments are ultimately resulting in the benefit of the rubber growers. In addition, it is important to show the benefits of such clonal material to farming community and popularize them. This again is related with making information available to farmers and a proper extension service. In addition, this necessitates the proper development of planting material and maintenance of nurseries to supply quality planting material to the farmer community. The issue of planting material is highlighted here since once planted, rubber trees stand for about 30 years and the mistake made at the inception is irreversible. Even if the farmers are efficient they will be limited by the performance of the planting material used losing profit all along the economic lifespan of the tree.

An interesting finding is that producers of sheet rubber were found to be less efficient than the producers of latex and majority of the smallholders were producers of sheet rubber. This may be due to recent expansion of latex products industry such as dipped rubber products and the improvements of markets for latex. However, majority of the smallholders are still producing sheet rubber. The low economic efficiency in sheet rubber producers implied that there is a loss of efficiency in either converting rubber latex to sheets or in selling rubber sheets. Accordingly, priority should be given to identify the setbacks in the production and marketing of sheet rubber.

\section{Acknowledgements}

This work has been undertaken with the financial support of the Council for the Agricultural Research Policy. We are extremely thankful to the Advisory 
Services Department at the Rubber Research Institute of Sri Lanka for their assistance in collecting data. We especially thank all those smallholder rubber farmers who provided data for this study.

\section{References}

Abdulai, A and Huffman, W (2000). Structural adjustment and economic efficiency of rice farmers in northern Ghana. Economic Development \& Cultural Change 48(3), 504.

Ali, M and Flinn, J C (1989). Profit efficiency among Basmati rice producers in Pakistan Punjab. American Journal of Agricultural Economics 71(2), 303-310.

Basnayake, B M J K and Gunaratne, L H P (2001). Estimation of technical efficiency and it's determinants in the Tea small holding sector in the mid country Wet zone of Sri Lanka. Tropical Agricultural Research 14, 137-150.

Bravo-Ureta, B E and Pinheiro, A E (1993). Efficiency analysis of developing country agriculture: A review of the frontier function literature. Agricultural and Resource Economics Review 22(1).
Coelli, T (1996). A Guide to FRONTIER Version 4.1: A Computer Program for Stochastic Frontier Production and Cost Function Estimation. Armidale, Australia, Centre for Efficiency and Productivity Analysis.

Hollas, D R and Stansell, S R (1988). An examination of the effect of ownership form on price efficiency: proprietary, cooperative and municipal electric utilities. Southern Economic Journal 55(2), 336-350.

Kumbhakar, S C and Lovell, C A K (2003). Stochastic Frontier Analysis, Cambridge Univ Pr.

Lau, L J (1976). A characterization of the normalized restricted profit function* 1 . Journal of Economic Theory 12(1), 131-163.

Murillo-Zamorano, L R (2004). Economic Efficiency and Frontier Techniques. Journal of Economic Surveys 18(1), 3377.

Address for correspondence: Dr Jagath Edirisinghe, Department of Agribusiness Management, Faculty of Agriculture and Plantation Management, Wayamba University of Sri Lanka, Makandura, Gonavila (NWP)

e-mail: jagathed@yahoo.com 